\title{
Applicability of Ammonia Sensors for Controlling Environmental Parameters in Accommodations for Lamb Fattening
}

\author{
F. Javier García-Ramos $\mathbb{D D}^{1}{ }^{1}$ A. Javier Aguirre $\mathbb{D}^{\mathrm{D}},{ }^{2,3}$ Pilar Barreiro, ${ }^{4}$ Esperanza Horcas, ${ }^{5}$ \\ Antonio Boné, ${ }^{1}$ and Mariano Vidal ${ }^{1}$
}

${ }^{1}$ Escuela Politécncia Superior, University of Zaragoza, C/Cuarte s/n, 22004 Huesca, Spain

${ }^{2}$ Faculty of Agricultural Sciences, University of Cuenca, Cuenca, Ecuador

${ }^{3}$ Prometeo Project, Secretary for Higher Education, Science, Technology and Innovation, Quito, Ecuador

${ }^{4}$ School of Agricultural, Food and Biosystems Engineering, Polytechnic University of Madrid, Madrid, Spain

${ }^{5}$ Carnes Oviaragon S.C.L. Carretera Cogullada, Mercazaragoza, Zaragoza, Spain

Correspondence should be addressed to F. Javier García-Ramos; fjavier@unizar.es

Received 1 October 2017; Accepted 28 January 2018; Published 27 March 2018

Academic Editor: Fernando Benito-Lopez

Copyright (c) 2018 F. Javier García-Ramos et al. This is an open access article distributed under the Creative Commons Attribution License, which permits unrestricted use, distribution, and reproduction in any medium, provided the original work is properly cited.

\begin{abstract}
Electrochemical ammonia sensors were used to analyse the existing relationship between the ammonia concentration and ambient levels of both temperature and relative humidity in commercial lamb fattening housing equipped with mechanical ventilation and straw-bedded pens. In the first stage of the experiment, sensors were placed over straw beds covered in lamb urine and analysed under laboratory conditions in order to determine ammonia emission evolution over time; three control temperatures $(25,35$, and $50^{\circ} \mathrm{C}$ ) were used. A HOBO $\mathrm{H} 8$ temperature and relative humidity logger and a Dräger $\mathrm{NH}_{3} \mathrm{LC}-6809680$ electrochemical ammonia sensor placed in a Dräger Polytron 7000 gas detector were utilized as sensors. A positive correlation was established between both ammonia emission time and emitted amount with temperature. Additionally, tests were performed in a commercial lamb housing to determine ammonia concentration variation with respect to height from the ground; three ammonia sensors placed at 50,90, and $135 \mathrm{~cm}$ above the ground were used simultaneously. The ammonia concentration significantly decreased as height increased. A $90 \mathrm{~cm}$ height was selected, and three ammonia probes were placed in three different pens inside the livestock housing, along with temperature and relative humidity sensors; four different housing ventilation rates were then tested under real conditions over a time period of 4 months. An adjustment polynomial equation between the housing ambient temperature and the ammonia concentration was obtained with $R^{2}=0.632$. In conclusion, a relationship can be established between temperature and ammonia concentration in commercial lamb housing under certain handling conditions, which in turn allows for estimating the ammonia concentration adequately based on the ambient internal temperature.
\end{abstract}

\section{Introduction}

Numerous studies related to animal welfare in intensive livestock housing show the sizable impact that environmental parameters have on animal health and production rates, as well as the relationship between those parameters and the type of animal handling employed [1].

In the case of sheep, the majority of studies have been carried out in dairy housing $[2,3]$; indeed, no rigorous studies have been completed with respect to housing for fattening lambs intended for meat consumption.

The main environmental parameters conditioning animal welfare in sheep housing are ambient temperature, relative humidity, and harmful gas concentration [3]. These parameters depend on the facilities and the type of sheep handling in the feedlot-concerning, for example, ventilation, the type of bedding covering the pen floor, and livestock density, among others. 
High temperatures inside livestock housing promote high breathing rates and heat stress [4]. As such, [2] recommend an ideal temperature range of $5-25^{\circ} \mathrm{C}$ and a relative humidity below $70 \%$.

On a different note, high concentrations of harmful gases may harm sheep. For example, [5] concluded that high concentrations of ammonia $\left(34 \mathrm{mg} / \mathrm{m}^{3}\right)$ cause temporary inflammation of the respiratory system and a decrease in daily weight gain. Reference [2] recommend ammonia levels below 10 ppm and $\mathrm{CO}_{2}$ levels below 2500 ppm.

Generally, analysing the concentrations of different harmful gases in sheep pens shows low values for $\mathrm{H}_{2} \mathrm{~S}$ and $\mathrm{CO}_{2}$; meanwhile, ammonia is the gas that most often reaches harmful levels [6]. Ammonia emissions inside housings for lamb fattening essentially come from the pen bedding $[7,8]$, which is usually made of straw and used by animals for excretion; for this reason, they should be replaced on a frequent basis.

Mechanical ventilation is employed to control gas concentration levels inside housings. On the other hand, heating systems are not used in sheep housing, meaning that ventilation also serves to regulate indoor temperature and relative humidity. Accordingly, [9], when analysing dairy sheep raised in a Mediterranean summer climate, concluded that an average ventilation rate of $66 \mathrm{~m}^{3} /($ sheep $\mathrm{h}$ ) would result in optimal conditions with respect to both their growth and well-being. These conclusions were supported by subsequent studies [10]. Reference [11] recommend that extractors eliminate $3 \mathrm{~m}^{3}$ of air per $1 \mathrm{~kg}$ of live weight per $\mathrm{h}$ to maintain appropriate ammonia levels. In the case of lambs, [2] recommend ventilation rates of $35 \mathrm{~m}^{3} / \mathrm{h}$ and animal in the summer and $20 \mathrm{~m}^{3} / \mathrm{h}$ and animal in the winter.

In order to establish ventilation rates in sheep housing, outdoor temperature and relative humidity are usually employed as a reference [12]. These parameters help to determine programmed operation times for ventilators and extractors.

However, measuring external parameters might not be the best method for controlling the environmental conditions within housings; in fact, it might make more sense to measure the primary internal environmental parameters directly [13]. Alternatively, environmental parameters could be bypassed entirely in favour of measuring the body temperature of animals - after all, this factor is a direct cause of thermal stress. Contact thermometers, infrared thermometers, and thermal lamps are all potential methods $[10,14,15]$; however, these types of measurements are challenging, expensive, and difficult to automate.

As opposed to temperature and relative humidity sensors, ammonia sensors provide an added benefit in that they reveal valuable information about environmental quality and adequate ventilation, since ammonia levels depend exclusively on internal conditions. Several studies have successfully employed commercial ammonia sensors in sheep housing [6, 16-18]. Alternatively, low-cost sensors that specifically fit housing features may be developed. For instance, [19] designed a low-cost system for measuring temperature, relative humidity, and ammonia and carbon dioxide concentration in livestock housing.
Given a lack of specific information, this paper analysed the data provided by ammonia sensors in sheep housing and compares their output with information provided by classic temperature and relative humidity sensors. First, these features were studied in the laboratory, under controlled conditions. Afterwards, measurements were carried out in a commercial sheep feedlot, under normal working conditions. This data was then used to estimate the importance of ammonia sensors for sheep handling in commercial housing, based on the primary management parameters of necessary ventilation, recommended livestock density, and bed handling.

\section{Materials and Methods}

2.1. Sensors. The following sensors were used to carry out measurements:

(1) Temperature and relative humidity: $\mathrm{HOBO} \mathrm{H} 8$ outdoor environment logger. Temperature range -30 to $50^{\circ} \mathrm{C}$, precision $\pm 0.2^{\circ} \mathrm{C}$; humidity range $0-100 \%$, precision $\pm 3 \%$

(2) Ammonia: $\mathrm{NH}_{3} \mathrm{LC}-6809680$ Dräger Sensor. Electrochemical sensor, capable of measuring ammonia concentrations in a range of $0-200 \mathrm{ppm}$ with a precision of $1 \mathrm{ppm}$, over a temperature range of $-40-65^{\circ} \mathrm{C}$. The sensor is placed in a gas detector (Dräger Polytron 7000) and connected to a control unit (Dräger QuadGard) that collects data in real time, stores it in a data logger (Madgetech OctProcess), and processes it with an accompanying software package (Madge Tech 2.03.14.)

2.2. Laboratory Study of Ammonia Emissions. The base material for the laboratory analysis was a reproduction of the bed normally used in lamb pens. Barley straw was placed and superficially compressed in a $0.062 \mathrm{~m}^{2}$ plastic tray. Each tray was filled with $124 \mathrm{ml}$ of urine. This amount was calculated considering the daily urine corresponding to the tray area, given the daily dejection of 1 lamb (1 l/lamb) and a density of $0.5 \mathrm{~m}^{2} / \mathrm{lamb}$. Urine had come from lambs housed at the University of Zaragoza and had been stored and refrigerated prior to use. A chemical laboratory analysis [20] revealed a nitrogen content of $2 \%$.

The tray was placed in a stove (J.P Selecta, Digitronic Series 2000), within which the ammonia sensor was set in the gas detector. The detector was connected to the control unit for data collection. The temperature and relative humidity logger was also set. Before placing each sample inside, the stove was programmed to maintain a constant temperature.

A factorial trial with temperatures of 25,35 , and $50^{\circ} \mathrm{C}$ was employed. Three bed trays $(N=9)$ were used for each temperature. The variables of interest were total time of gas emission (TTGE), indoor temperature, indoor relative humidity, ammonia (ppm), emission speed, and residual moisture in each bed after $24 \mathrm{~h}$; with the exception of the last variable, which was measured only once at the end of the experiment, each one was measured for $24 \mathrm{~h}$, with observations recorded every $10 \mathrm{~s}$. 
TABLE 1: Data collecting periods and ventilation rates for the superficial distribution analysis of ammonia.

\begin{tabular}{lccccc}
\hline Date & $\begin{array}{c}\text { Number of measurements } \\
(1 \text { measurement/min })\end{array}$ & $\begin{array}{c}\text { Average indoor } \\
\text { temperature }\left({ }^{\circ} \mathrm{C}\right)\end{array}$ & Air changes/h & Ventilation flow $\left(\mathrm{m}^{3} / \mathrm{h}\right)$ & Ventilation rate \\
\hline July 2005 & 23,645 & 24.5 & 20.1 & 191,400 & V1 \\
July-September 2005 & 51,729 & 22.8 & 15.2 & 145,000 & V2 \\
January 2016 & 16,383 & 11.5 & 2.34 & 22,330 & V3 \\
May-July 2016 & 16,385 & 22.0 & 6.07 & 58,000 & V4 \\
\hline
\end{tabular}

Once the temperature inside the stove stabilized, the tray was placed inside and the probes were activated. Each sample remained inside the stove for $24 \mathrm{~h}$. At the end of the trial, the tray was removed and weighed on a scale (Sartorius BL600; precision: $0.1 \mathrm{~g}$ ).

The emission time reflects the length of time in which the gas detector showed ammonia levels above zero; an emission curve was generated for this period in order to estimate the maximum (peak) and average values, as well as total quantity and emission rate.

The normality and homoscedasticity of the dependent variables were measured by means of the Shapiro-Wilk and Levene's tests, respectively. When necessary, the variable was transformed by Napierian logarithms or a specific coefficient. The relation between these two was measured using the Pearson correlation coefficient. Differences between dependent variable averages were evaluated through an analysis of variance (general linear model (GLM)) of one factor, using the indoor temperature as fixed. Differences between temperature levels were measured using Tukey's post hoc test and then assigned a letter when the level of significance was below $5 \%[21]$.

\subsection{Commercial Lamb Feedlot Study}

2.3.1. Impact of the Ammonia Sensor Height. During the first stage of testing, the impact of sensor height was evaluated. Tests were performed in a commercial feedlot consisting of 42 blocks over an area of $1272 \mathrm{~m}^{2}$; livestock density in the monitored pens was approximately $1 \mathrm{~m}^{2} / \mathrm{lamb}$. The feedlot air volume was $9540 \mathrm{~m}^{3}$. The feedlot was the property of Pastores Grupo Cooperativo and was located in Santa Cilia de Jaca (Huesca, Spain); it housed animals in pens with reinforced concrete floors covered with a barley straw bedding of approximately $10 \mathrm{~cm}$ thickness. Measurements were carried out under real working conditions at a ventilation rate of 20.1 air changes per $h$.

The gas detectors were screwed to a metallic post at heights of 50, 90, and $135 \mathrm{~cm}$ above the bed surface. Data were recorded at a frequency of $1 \mathrm{scan} / \mathrm{min}$ and were divided into four periods, corresponding to the first $8 \mathrm{~d}$, the next $7 \mathrm{~d}$, the following $3 \mathrm{~d}$, and the final $12 \mathrm{~d}$. These time periods were tagged as weeks $1,2,3$, and 4 , respectively.

Normality and homoscedasticity were individually analysed for each variable, transforming the variable when necessary. Differences between temperatures and indoor relative humidity in the test periods were measured by a GLM of one factor. Correlations between indoor ammonia quantity, temperature, and relative humidity were obtained

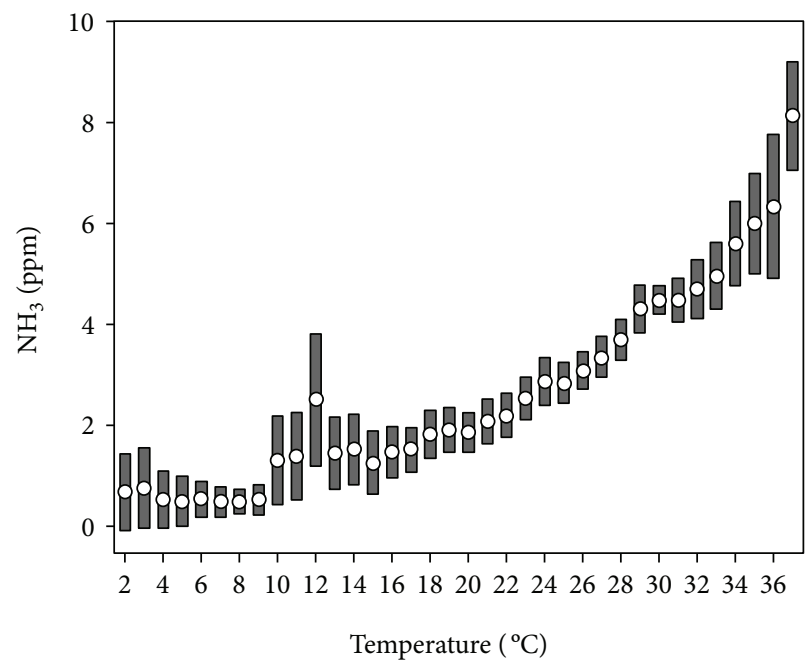

Figure 1: Mean and 95\% confidence intervals of the ammonia concentration according to the indoor temperature of the livestock housing, including all ventilation regimes, throughout the study period

using Spearman's rank correlation coefficient. For measuring the difference between recorded ammonia concentration averages for different probe heights, a covariance analysis with two factors was employed: (1) height: 50, 90, and $135 \mathrm{~cm}$; and (2) week, using temperature as a covariate. Different letters indicate significant differences $(P<0.05)$ for all GLMs, as determined by Tukey's post hoc test [21].

A linear relationship between ammonia concentration and both temperature and relative humidity was tested using a linear regression for each probe height. Another regression included the probe height with a combination of all observations [22].

For all GLMs, the adjusted coefficient of determination $\left(R^{2}{ }_{\text {ad }}\right)$ is shown. SAS 9.4 software (SAS Institute Inc.) was used for all analyses.

2.3.2. Measurement of Environmental Parameters under Real Working Conditions. In the same commercial feedlot described above, three ammonia sensors were placed in three different pens over two differentiated time periods corresponding to the years 2005 and 2006. This testing included the summer seasons, which present the highest temperatures inside the feedlot (Table 1). Temperature and relative humidity inside the feedlot were measured during this period. Data were sampled for all sensors at a frequency of $1 \mathrm{~min}$. The ventilation rates were established by the property owners, seeing how this trial was meant to analyse real working conditions 
TABLE 2: Correlations between the sheep urine ammonia emission variables.

\begin{tabular}{|c|c|c|c|c|c|c|c|c|}
\hline Variables & & TTGE (h) & Indoor temp $\left({ }^{\circ} \mathrm{C}\right)$ & $\begin{array}{c}\text { Indoor relative } \\
\text { humidity }\end{array}$ & $\begin{array}{c}\mathrm{NH}_{3} \\
\text { maximum }\end{array}$ & $\mathrm{NH}_{3}$ average & $\mathrm{NH}_{3}$ sum & $\begin{array}{c}\mathrm{NH}_{3} \text { emission rate } \\
(\mathrm{ppm} / \mathrm{s})\end{array}$ \\
\hline \multirow{2}{*}{ TTGE (h) } & $R$ & 1 & 0.534 & -0.679 & 0.723 & 0.003 & 0.995 & -0.001 \\
\hline & $P$ & & 0.138 & 0.044 & 0.028 & 0.995 & $<0.001$ & 0.999 \\
\hline \multirow{2}{*}{ Indoor temperature $\left({ }^{\circ} \mathrm{C}\right)$} & $R$ & & 1 & -0.950 & 0.860 & 0.693 & 0.607 & 0.691 \\
\hline & $P$ & & & $<0.001$ & 0.003 & 0.038 & 0.083 & 0.039 \\
\hline \multirow{2}{*}{ Indoor relative humidity } & $R$ & & & 1 & -0.864 & -0.561 & -0.738 & -0.558 \\
\hline & $P$ & & & & 0.003 & 0.116 & 0.023 & 0.119 \\
\hline \multirow{2}{*}{ Maximum $\mathrm{NH}_{3}$} & $R$ & & & & 1 & 0.686 & 0.786 & 0.683 \\
\hline & $P$ & & & & & 0.041 & 0.012 & 0.042 \\
\hline \multirow{2}{*}{ Average $\mathrm{NH}_{3}$} & $R$ & & & & & 1 & 0.100 & 1.000 \\
\hline & $P$ & & & & & & 0.797 & $<0.001$ \\
\hline \multirow{2}{*}{ Total $\mathrm{NH}_{3}$} & $R$ & & & & & & 1 & 0.097 \\
\hline & $P$ & & & & & & & 0.804 \\
\hline \multirow{2}{*}{$\mathrm{NH}_{3}$ emission rate $(\mathrm{ppm} / \mathrm{s})$} & $R$ & & & & & & & 1 \\
\hline & $P$ & & & & & & & \\
\hline
\end{tabular}

$R$ : Pearson product-moment correlation coefficient; $P$ : $P$ value.

TABLE 3: Least square mean values for emission time, indoor relative humidity, variables related to ammonia concentration, and residual moisture in the straw bed.

\begin{tabular}{|c|c|c|c|c|c|c|}
\hline \multirow{2}{*}{ Variables } & \multicolumn{3}{|c|}{ Temperature $\left({ }^{\circ} \mathrm{C}\right)$} & \multicolumn{3}{|c|}{ Probability } \\
\hline & 25 & 35 & 50 & SEM & $R_{\mathrm{ad}}^{2}$ & $P$ value \\
\hline Emission time $(\mathrm{h})$ & $0.270^{\mathrm{a}}$ & $0.238^{\mathrm{a}}$ & $1.184^{\mathrm{b}}$ & 0.226 & 0.73 & 0.016 \\
\hline Indoor relative humidity & $0.4^{\mathrm{b}}$ & $0.3^{\mathrm{b}}$ & $0.1^{\mathrm{a}}$ & 0.03 & 0.90 & $<0.001$ \\
\hline Maximum $\mathrm{NH}_{3}(\mathrm{ppm})$ & $1.2^{\mathrm{a}}$ & $1.82^{\mathrm{a}}$ & $7.2^{\mathrm{b}}$ & 1.56 & 0.66 & 0.016 \\
\hline Average $\mathrm{NH}_{3}(\mathrm{ppm})$ & 0.9 & 1.0 & 2.5 & 0.71 & 0.32 & 0.131 \\
\hline Total $\mathrm{NH}_{3}(\mathrm{ppm})$ & $96.7^{\mathrm{a}}$ & $96.3^{\mathrm{a}}$ & $1148.7^{\mathrm{b}}$ & 61.03 & 0.98 & $<0.001$ \\
\hline $\mathrm{NH}_{3}$ emission rate $(\mathrm{ppm} / \mathrm{s})$ & 0.09 & 0.11 & 0.17 & 0.03 & 0.30 & 0.175 \\
\hline Moisture (straw bed) & $0.27^{\mathrm{a}}$ & $0.28^{\mathrm{b}}$ & $0.28^{\mathrm{b}}$ & 0.00 & 0.88 & 0.002 \\
\hline
\end{tabular}

SEM: standard error of the mean. Different superscripts $(a, b)$ denote significant differences $P<0.05$.

TABLE 4: Number of observations $(N)$, mean, and standard deviation (SD) of indoor temperature and relative humidity for every period that the test was performed.

\begin{tabular}{lcccccccccccc}
\hline Week & \multicolumn{3}{c}{$1(5-13 /$ May/05) } & \multicolumn{2}{c}{$2(13-20 /$ May/2005) } & \multicolumn{2}{c}{$3(14-17 /$ Jun/05) } & \multicolumn{2}{c}{$4(17-29 /$ Jun/05) } \\
\hline Variables & $N$ & Mean & SD & $N$ & Mean & SD & $N$ & Mean & SD & $N$ & Mean & SD \\
Temperature $\left({ }^{\circ} \mathrm{C}\right)$ & 33,660 & $16.4^{\mathrm{b}}$ & 4.31 & 29,400 & $14.8^{\mathrm{a}}$ & 3.9 & 13,590 & $21.7^{\mathrm{c}}$ & 4.5 & 49,149 & $27.4^{\mathrm{d}}$ & 4.3 \\
HR (\%) & 33,660 & $63.1^{\mathrm{c}}$ & 15.5 & 29,400 & $65.6^{\mathrm{d}}$ & 12.2 & 13,590 & $59.7^{\mathrm{b}}$ & 13.8 & 49,149 & $47.7^{\mathrm{a}}$ & 15.5 \\
\hline
\end{tabular}

Different superscripts (a, b, c, d) denote significant differences $P<0.05$.

(Table 1). Livestock density inside the monitored pens was approximately $1 \mathrm{lamb} / \mathrm{m}^{2}$.

The ammonia concentration was adjusted according to the indoor livestock housing temperature. To this effect, the data were clustered in four blocks according to ventilation rate (V1-V2-V3-V4). The temperature data were clustered in ranges of $1^{\circ} \mathrm{C}$, so that the ammonia values associated with the temperature ranges (Figure 1) can be related.

Lambs entered the analysed housings with an average live weight of $17 \mathrm{~kg}$ and were fattened until they reached a weight between 22 and $29 \mathrm{~kg}$ (depending on the destination market); as such, they tended to remain for 30 to $45 \mathrm{~d}$.

\section{Results and Discussion}

3.1. Laboratory Study of Ammonia Emission. The ammonia concentration recorded during the laboratory test ranged from 0 to 9.813 ppm, based on a total of 77,563 observations. Table 2 shows the Pearson correlation coefficient between studied variables. 


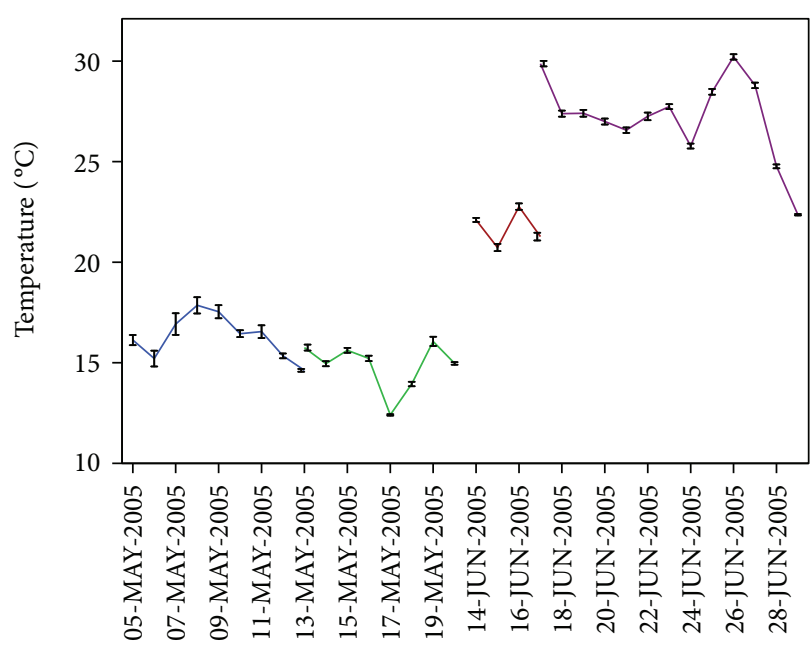

Date

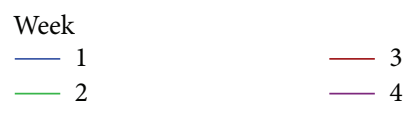

(a)

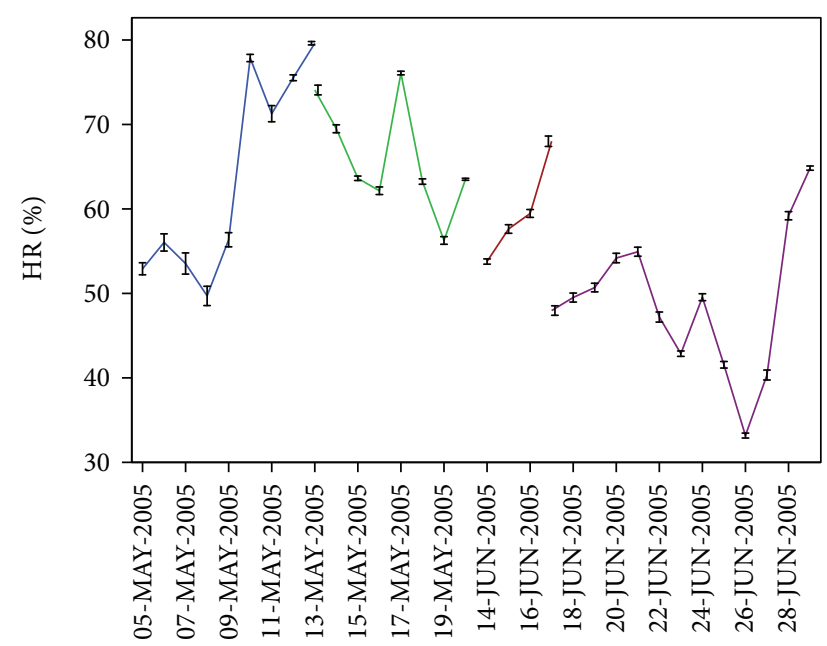

Date

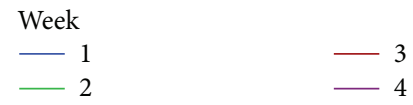

(b)

Figure 2: Confidence intervals at 95\% of temperature (a) and relative humidity (b) mean values recorded during the test weeks.

TABLE 5: Least square mean values of ammonia concentration (ppm) with respect to the height at which the probes were placed.

\begin{tabular}{lcccccccc}
\hline \multirow{2}{*}{ Variable } & \multicolumn{3}{c}{ Height $(\mathrm{cm})$} & \multirow{2}{*}{ SED } & $R^{2}$ & \multicolumn{4}{c}{$P$ value } \\
& 50 & 90 & 135 & & & Height & Week & $\mathrm{H} \times \mathrm{W}$ \\
\hline $\mathrm{NH}_{3}$ & $7.9^{\mathrm{c}}$ & $5.6^{\mathrm{b}}$ & $4.5^{\mathrm{a}}$ & 0.11 & 0.31 & $<0.001$ & $<0.001$ & $<0.001$
\end{tabular}

H: height; W: week. SED: standard error of the difference between means. Different superscripts (a, b, c) denote significant differences $P<0.05$.

As observed, the emission time was significantly and positively correlated to the total emitted amount and the maximum emission peak, while also negatively correlated to the indoor relative humidity. The indoor temperature was significantly and negatively correlated to the relative humidity, as well as positively correlated to the maximum ammonia quantity, average ammonia quantity, and emission rate; it was nearly significant for the total emitted amount. Meanwhile, the relative humidity shows a negative and significant correlation with the maximum emitted ammonia quantity, total emitted ammonia quantity, and emission rate. On the other hand, all variables related to ammonia emissions show significant and positive correlations with each other. The residual moisture in the bed does not show a correlation with any of the studied variables.

Table 3 shows the difference between dependent variable mean values using indoor temperature as fixed. In general, significant changes take place in most variables beyond a temperature of $35^{\circ} \mathrm{C}$; the behaviour of ammonia-related variables does not vary linearly with temperature, since values are similar between 25 and $35^{\circ} \mathrm{C}$ and only increase significantly at $50^{\circ} \mathrm{C}$. On the one hand, emission time, maximum emitted ammonia peak, total quantity, and residual moisture in the bed increased. On the other hand, indoor relative humidity decreased. Differences between temperature

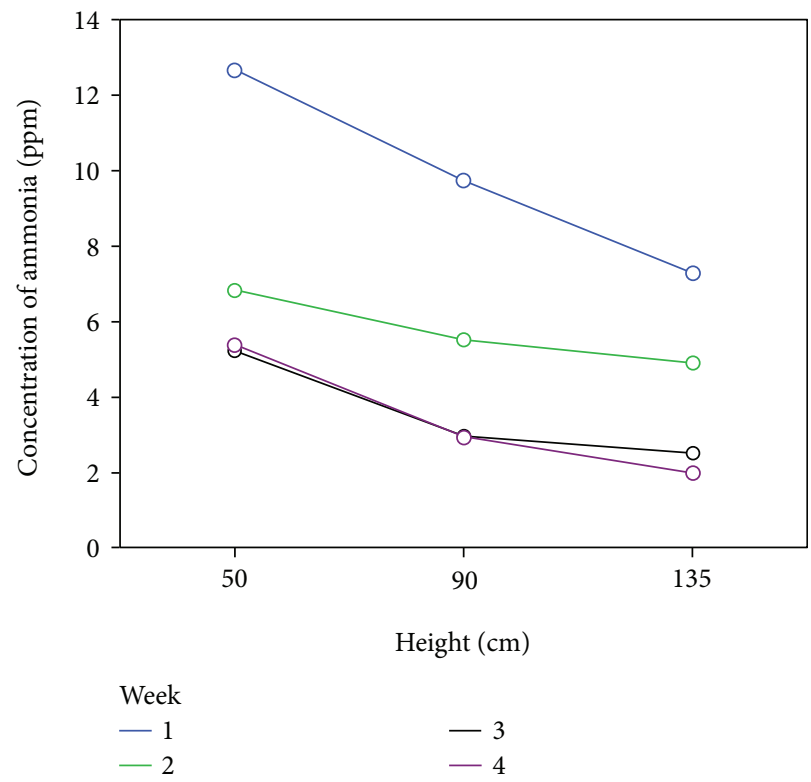

FIGURE 3: Least square mean values of ammonia concentration according to the probe height and week.

values, average quantity of emitted ammonia, and emission rate are not shown. Nevertheless, adjustments in these two variables through a linear model show a maximum reliability of $32 \%\left(R_{\text {ad }}^{2}\right.$ of average ammonia and emission rate, Table 3).

3.2. Impact of Probe Height on Observed Ammonia Concentration. The temperature, which ranged from 7 to $35.7^{\circ} \mathrm{C}$ during the test, shows significant variation between weeks $\left(P<0.001 ; R_{\text {ad }}^{2}=0.643\right)$. The relative humidity, which 
TABLE 6: Linear regression parameters between ammonia concentration and environmental variables.

\begin{tabular}{lcccrc}
\hline Height $(\mathrm{cm})$ & Constant & $\times$ Temperature $\left({ }^{\circ} \mathrm{C}\right)$ & $\times$ Relative humidity & $\times$ Height $(\mathrm{cm})$ & $R_{\text {ad }}^{2}$ \\
\hline 50 & 0.267 & 0.288 & - & - & 0.171 \\
90 & 4.375 & 0.116 & -0.044 & - & 0.145 \\
135 & 1.403 & 0.142 & -0.016 & - & $<0.001$ \\
All & 6.287 & 0.174 & -0.033 & -0.037 & 0.123 \\
\hline
\end{tabular}

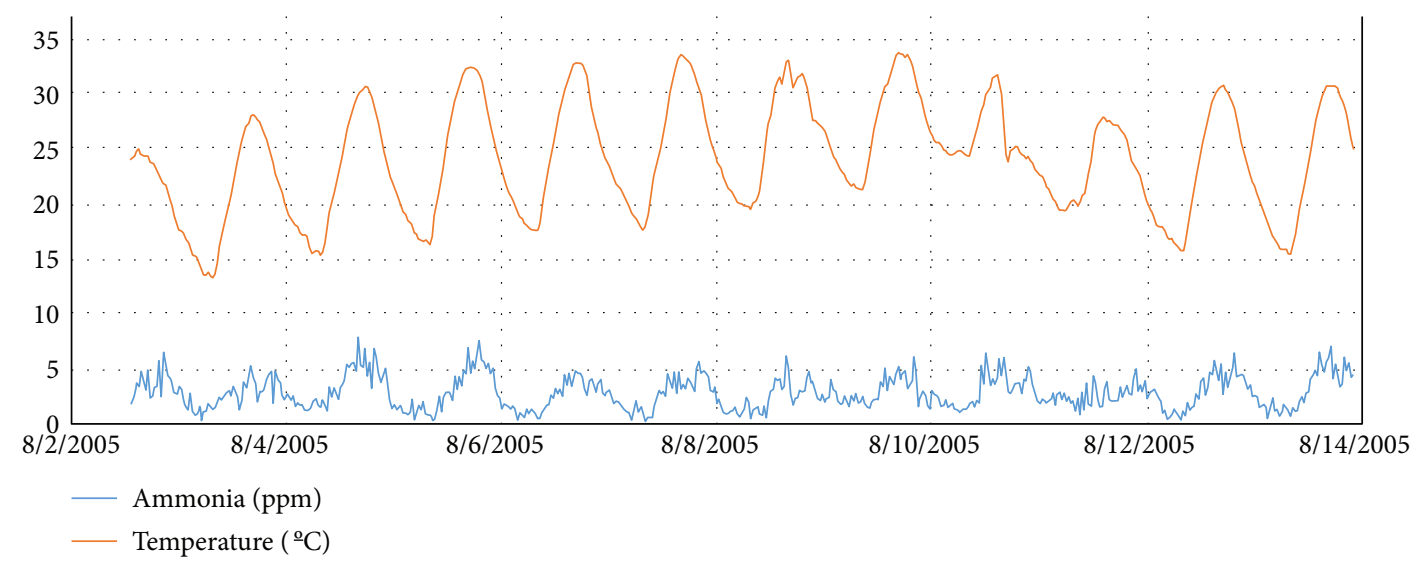

FIgURE 4: Ammonia concentration and temperature values under V2 conditions (15.2 air changes per h) over a consecutive 11-day time period.

showed values between $18.7 \%$ and $89 \%$, also varied significantly $\left(P<0.001 ; R_{\text {ad }}^{2}=0.246\right.$; Table 4 and Figure 2$)$.

Findings show a significant correlation $(P<0.001)$ between ammonia concentration, indoor temperature, and relative humidity; a strongly negative correlation between temperature and relative humidity $($ Rho $=-0.360)$; and a positive correlation between ammonia and temperature $($ Rho $=0.383)$. These results match those provided by [23], who found a positive correlation between temperature and ammonia concentration.

The detected ammonia concentration increased significantly as the height at which the probe was placed decreased (Table 5). A significant impact was observed for the measurement weeks and the interaction between both factors, due to the variation in the temperature and relative humidity between weeks (Figure 3). Reference [6] also showed higher ammonia concentrations for lower heights in measurements carried out during transport of sheep by ship. This is reasonable, since ammonia is released from animal excreta, which accumulates on the pen floor [18]. The linear relationship between ammonia concentration and environmental variables was significant for all three heights, in such way that the adjustment between what was previously established by the equation and the observations decreased as the height of the probe increased (Table 6).

3.3. Measurement of Environmental Parameters under Real Working Conditions. Figure 4 shows a temporal series of ammonia concentration and temperature values in one of the livestock housing pens under real ventilation conditions with 15.2 air changes per $h$. The data reveal a clear

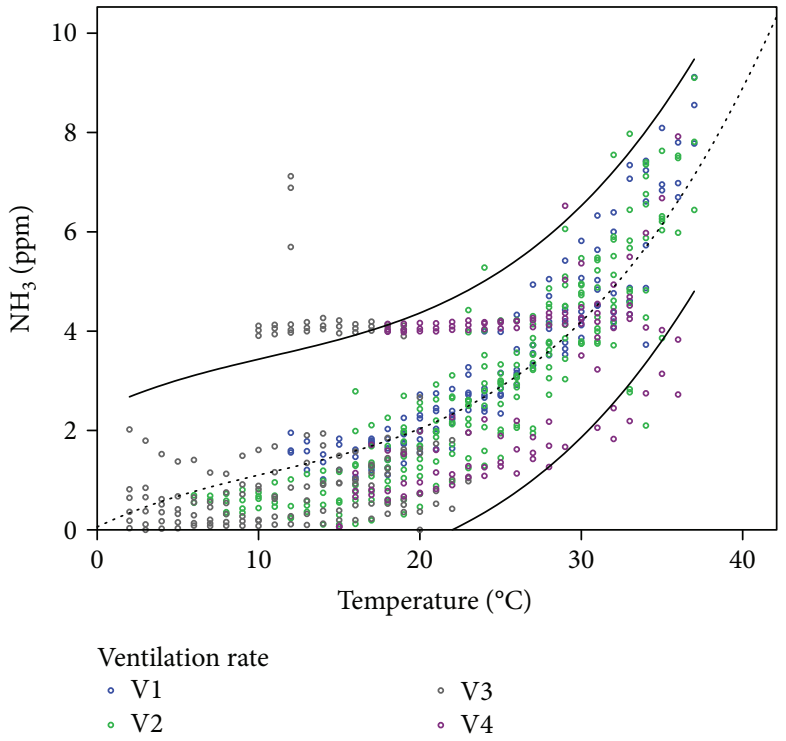

FIGURE 5: Adjustment third-degree polynomial equation between the concentration of ammonia and the temperature, taking into account the four rates of ventilation $(\mathrm{V} 1=20.1$ changes $/ \mathrm{h} ; \mathrm{V} 2=$ 15.2 changes $/ \mathrm{h} ; \mathrm{V} 3=2.34$ changes $/ \mathrm{h} ;$ and $\mathrm{V} 4=6.07$ changes $/ \mathrm{h})$. $\left[\mathrm{NH}_{3}\right]=0.06+(0.15 \times \mathrm{T})-(0.00719 \times \mathrm{T} 2)+(0.000222 \times \mathrm{T} 3) ; \quad R_{\mathrm{ad}}^{2}=$ 0.632; $P<0.001$. 95\% confidence interval with the standard error of the observations.

correspondence between the two parameters, in line with what was observed in the laboratory tests.

The relationship between the ammonia concentration and the temperature follows an increasing trend, the 
variability of which appears to be highest in the $10-14^{\circ} \mathrm{C}$ range and from $32^{\circ} \mathrm{C}$ (Figure 1).

An adjustment equation (Figure 5) was obtained based on all the ventilation rate data. These data were chosen as they presented a rather wide temperature range that could be extrapolated to all seasons of the year. The adjustment equation was a third-degree polynomial equation with an $R^{2}$ of 0.632 that tracks average ammonia concentration according to ambient temperature.

In this way, almost $65 \%$ of the variation of the observations was explained. It should be noted that, between 10 and $30^{\circ} \mathrm{C}$, the ventilation rates $\mathrm{V} 3$ and $\mathrm{V} 4$ are not able to adequately decrease the concentration of ammonia, with values around $4 \mathrm{ppm}$. This value does exceed the harmful threshold for the animals [2]; however, the results show an evident and significant lack of effectiveness with respect to the other ventilation rates.

These results show that it is feasible to estimate ammonia concentration knowing the indoor ambient temperature of livestock housing. Of course, the adjustment equation is linked to the usual handling conditions of the housing, such as the type of bed, livestock density, and ventilation rates. Based on these results, choosing the lowest analysed ventilation rate seems reasonable, since it showed low ammonia concentrations while keeping an ammonia-temperature relation similar to that of the remaining ventilation rates.

\section{Conclusions}

Using ammonia, temperature, and relative humidity sensors inside sheep housing provides relevant information for establishing housing ventilation rates based on strong technical criteria, without relying exclusively on the temperature and relative humidity outside the feedlot.

In the case of sheep housings with straw beds, ammonia concentrations decrease as distance from the ground increases. Therefore, it is essential to place the sensors at the level where the animals breathe.

It is possible to establish equations with high correlation coefficients that associate indoor housing temperature with ammonia concentration, specifically for sheep housing with straw beds and mechanical ventilation set to a specific rate. These equations provide reasonable errors over a wide range of ventilation conditions that are regularly used in sheep housing in areas with a Mediterranean climate.

\section{Conflicts of Interest}

The authors declare that they have no conflicts of interest.

\section{References}

[1] J. Hartung, "The effect of airborne particulate on livestock health and production," in Pollution in Livestock Production System, I. Ap Dewi, R. F. E. Axford, I. F. M. Marai, and H. Omed, Eds., pp. 55-69, CAB international, Wallingford, UK, 1994.

[2] A. Sevi, D. Casamassima, G. Pulina, and A. Pazzona, "Factors of welfare reduction in dairy sheep and goats," Italian Journal of Animal Science, vol. 8, no. sup1, Supplement 1, pp. 81-101, 2009.

[3] M. Caroprese, "Sheep housing and welfare," Small Ruminant Research, vol. 76, no. 1-2, pp. 21-25, 2008.

[4] A. Sevi, G. Annicchiarico, M. Albenzio, L. Taibi, A. Muscio, and S. Dell'Aquila, "Effects of solar radiation and feeding time on behavior, immune response and production of lactating ewes under high ambient temperature," Journal of Dairy Science, vol. 84, no. 3, pp. 629-640, 2001.

[5] C. J. C. Phillips, M. K. Pines, M. Latter et al., "Physiological and behavioral responses of sheep to gaseous ammonia," Journal of Animal Science, vol. 90, no. 5, pp. 1562-1569, 2012.

[6] M. K. Pines and C. J. C. Phillips, "Microclimatic conditions and their effects on sheep behavior during a live export shipment from Australia to the Middle East," Journal of Animal Science, vol. 91, no. 9, pp. 4406-4416, 2013.

[7] F. J. García Ramos, P. Barreiro, V. Parejo, L. Lahera, and E. Horcas, Análisis de la concentración de amoniaco y su relación con otros parámetros ambientales en un cebadero de corderos, IV Congreso Nacional y I Congreso Ibérico de AgroIngeniería, Albacete (Spain), 2007.

[8] A. Sevi, M. Albenzio, A. Muscio, D. Casamassima, and P. Centoducati, "Effects of litter management on airborne particulates in sheep houses and on the yield and quality of ewe milk," Livestock Production Science, vol. 81, no. 1, pp. 1-9, 2003.

[9] A. Sevi, M. Albenzio, G. Annicchiarico, M. Caroprese, R. Marino, and L. Taibi, "Effects of ventilation regimen on the welfare and performance of lactating ewes in summer," Journal of Animal Science, vol. 80, no. 9, pp. 2349-2361, 2002.

[10] N. Koluman and I. Daskiran, "Effects of ventilation of the sheep house on heat stress, growth and thyroid hormones of lambs," Tropical Animal Health and Production, vol. 43, no. 6, pp. 1123-1127, 2011.

[11] S. Wolfensohn and M. Lloyd, Handbook of Laboratory Animal Management and Care, Blackwell Science, UK, 1998.

[12] K. De, D. Kumar, K. Kumar, A. Sahoo, and S. M. K. Naqvi, "Effect of different types of housing on behavior of Malpura lambs during winter in semi-arid tropical environment," Journal of Veterinary Behavior: Clinical Applications and Research, vol. 10, no. 3, pp. 237-242, 2015.

[13] C. Phillips, "The welfare risks and impacts of heat stress on sheep shipped from Australia to the Middle East," The Veterinary Journal, vol. 218, pp. 78-85, 2016.

[14] L. A. Aguayo-Ulloa, M. Pascual-Alonso, J. L. Olleta, C. Sañudo, G. C. Miranda-de la Lama, and G. A. María, "Effect of a screen with flaps and straw on behaviour, stress response, productive performance and meat quality in indoor feedlot lambs," Meat Science, vol. 105, pp. 16-24, 2015.

[15] T. do Prado Paim, B. O. Borges, P. de Mello Tavares Lima et al., "Thermographic evaluation of climatic conditions on lambs from different genetic groups," International Journal of Biometeorology, vol. 57, no. 1, pp. 59-66, 2013.

[16] J. Q. Ni and A. J. Heber, "Sampling and measurement of ammonia at animal facilities," Advances in Agronomy, vol. 98, pp. 201-269, 2008.

[17] C. J. Phillips, M. K. Pines, and T. Muller, "The avoidance of ammonia by sheep," Journal of Veterinary Behavior: Clinical Applications and Research, vol. 7, no. 1, pp. 43-48, 2012.

[18] Y. Zhang, A. T. Lisle, and C. J. C. Phillips, "Development of an effective sampling strategy for ammonia, temperature and 
relative humidity measurement during sheep transport by ship," Biosystems Engineering, vol. 155, pp. 12-23, 2017.

[19] T. M. Banhazi, "User friendly air quality monitoring system," Applied Engineering in Agriculture, vol. 25, no. 2, pp. 281290, 2009.

[20] AOAC, Official Methods of Analysis of AOAC INTERNATIONAL, Association of Analytical Communities, Gaithersburg, MD, USA, 2012.

[21] D. C. Montgomery and G. C. Runger, Applied Statistics and Probability for Engineers, John Wiley \& Sons, Inc, New York, NY, USA, 2003.

[22] D. Zelterman, Applied Linear Models with $S A S^{\circledR}$, Cambridge University Press, Cambridge, UK, 2010.

[23] M. K. Pines and C. J. C. Phillips, “Accumulation of ammonia and other potentially noxious gases on live export shipments from Australia to the Middle East," Journal of Environmental Monitoring, vol. 13, no. 10, pp. 2798-2807, 2011. 


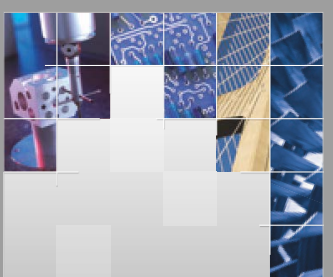

\section{Enfincering}
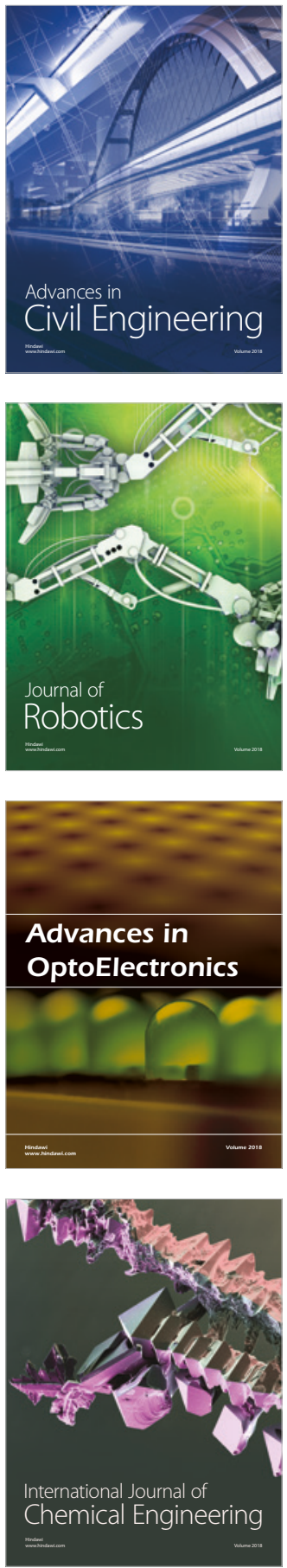

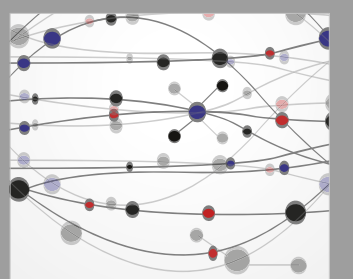

\section{Rotating \\ Machinery}

The Scientific World Journal

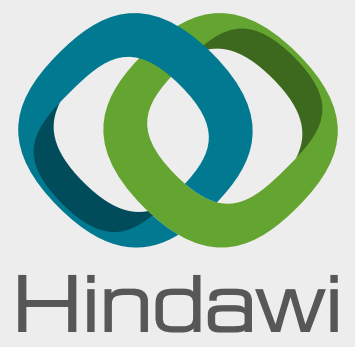

Submit your manuscripts at

www.hindawi.com
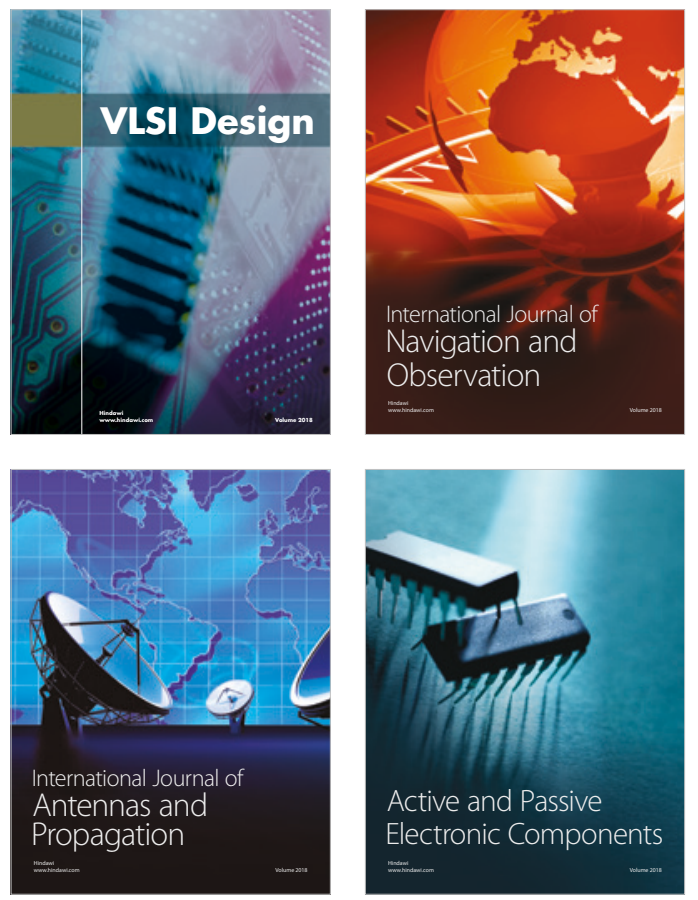
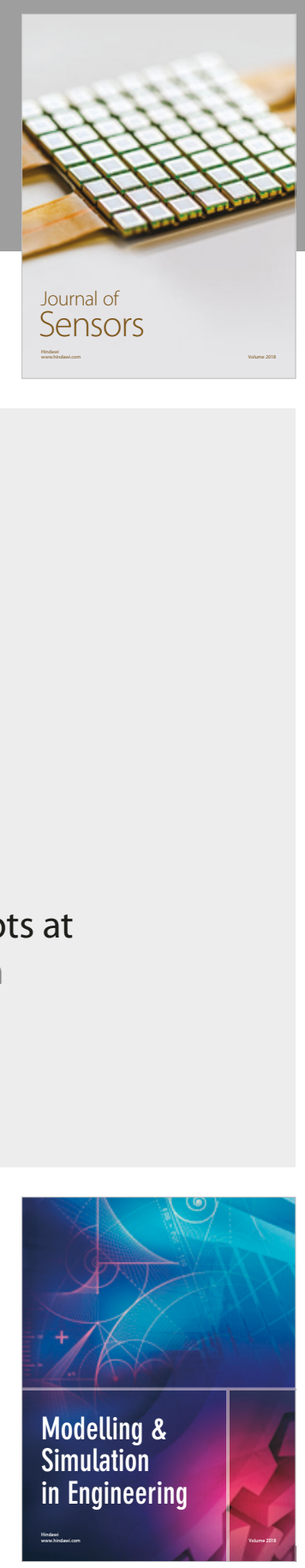

\section{Advances \\ Multimedia}
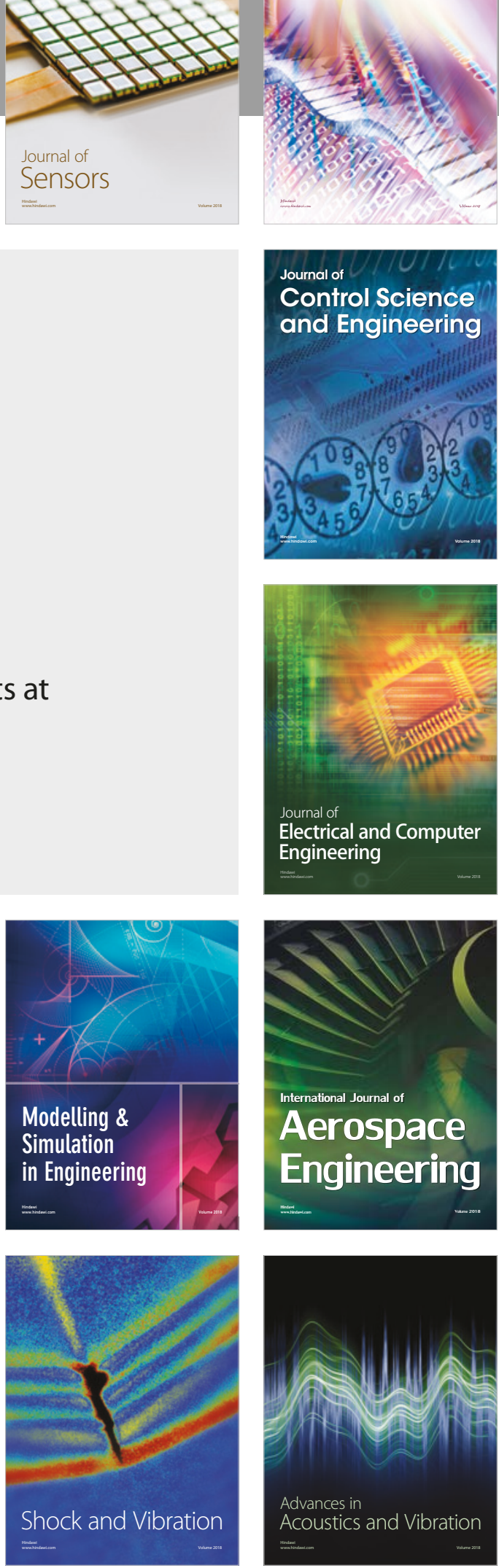